Gut, 1986, 27, 893-900

\title{
Effects of a new, concentrated wheat fibre preparation on intestinal transit, deoxycholic acid metabolism and the composition of bile
}

\author{
S N MARCUS AND K W HEATON \\ From the University Department of Medicine, Bristol Royal Infirmary, Bristol
}

SUMmaRY When the cholesterol saturation index of bile is reduced by wheat bran there is generally a fall in the deoxycholic acid content of bile. As the same effects occur with senna, bran might act on bile simply via its accelerating effect on colonic transit. We have studied the effects of a new, concentrated, wheat fibre preparation (Testa Triticum Tricum, Trifyba, which is $80 \%$ dietary fibre) upon bile composition, deoxycholic acid metabolism and intestinal transit time, and have assessed whether these effects are related. Twenty constipated volunteers were prescribed Testa Triticum Tricum in doses (10-32 g/day) sufficient to relieve their symptoms for at least six weeks. Before and at the end of this period, duodenal bile was sampled to enable measurement of deoxycholic acid pool (by isotope dilution), total bile acid pool, bile acid composition and cholesterol saturation index. Whole gut transit time fell from $120 \pm$ SD35 to $68 \pm 35$ hours. At the same time, biliary \%deoxycholic acid fell from $26 \cdot 6 \pm 12.0$ to $23.0 \pm 11 \cdot 8(\mathrm{p}=0.002)$, the total bile acid pool expanded from $2 \cdot 36 \pm 0.88$ to $2.75 \pm 0.90 \mathrm{~g}(\mathrm{p}=0.008)$ and cholesterol saturation index fell from $1.13 \pm 0.32$ to $1.07 \pm 0.29(p=0.04)$. In subjects with initial cholesterol saturation index over $1.0(n=12)$, it fell from $1.33 \pm 0.25$ to $1 \cdot 22 \pm 0.21 \quad(p=0.008)$. There was no significant correlation between change in saturation index and change in \%deoxycholic acid or deoxycholic acid pool, nor between any of these parameters and change in transit time. Testa Triticum Tricum reduces the cholesterol saturation index of supersaturated bile but this action appears to be independent of its effect on colonic transit and of changes in deoxycholic acid metabolism.

Several studies have shown that the administration of wheat bran lowers the cholesterol saturation of gall bladder bile, at least when this is initially supersaturated. ${ }^{1-4}$ The mode of action of bran has not been established. Initially, it was suggested that it acted by reducing the level of deoxycholic acid in bile $^{1}$ and in five studies reported between 1973 and 1978 bran did lower the proportion of deoxycholic acid in the bile acid pool. ${ }^{1-3}{ }^{6}{ }^{6}$ No such effect was found in two later studies. ${ }^{4}{ }^{7}$ In one of them ${ }^{7}$ the subjects were young and slim and they began with low levels of deoxycholic acid and were already on a high fibre diet. It was not surprising, therefore, that there was no change in the bile acid composition or the cholesterol saturation of their bile. In the other study, ${ }^{4}$ however, there was a clear fall in cholesterol saturation despite no change in deoxycholic acid

Address for correspondence: Dr K W Heaton, Department of Medicine, Bristol Royal Infirmary, Bristol BS2 8HW.

Received for publication 21 November 1985. levels. In view of the conflicting evidence, it seemed appropriate to examine in more detail the effects of wheat bran or, at least, of wheat fibre, upon deoxycholic acid metabolism, ensuring that some subjects had initially supersaturated bile.

If bran does act by reducing the deoxycholic acid content of bile this may be because of its laxative properties, such that, with faster transit of colonic contents, there is less time available for the formation or absorption of deoxycholic acid. We have previously shown that a chemical laxative, sennoside $B$, reduces both the deoxycholic acid pool and the cholesterol saturation of bile and that these changes correlate with each other and with changes in transit time. ${ }^{8}$ Lactulose has similar effects ${ }^{9}$ but the reduction in deoxycholic acid was attributed to acidification of the right colon.

The aim of the present study was to determine whether a new concentrated wheat fibre preparation was effective in lowering the cholesterol saturation index of bile and whether these effects were 
mediated through alterations in deoxycholic acid metabolism and specifically in the size of the deoxycholic acid pool. The latter has not previously been measured in subjects with supersaturated bile before and after supplementation with wheat fibre. We also wished to look for correlations between wheat fibre induced changes in whole gut transit time and changes in bile composition and deoxycholic acid metabolism.

\section{Methods}

SUBJECTS AND DESIGN OF STUDY

Constipated subjects were recruited in response to posters in local chemist shops and health centres, in accident and clinic waiting areas of the Bristol Royal Infirmary and Dental Hospital, and in WRVS stalls. Advertisements were also inserted in the University Newsletter and health authority gazette and letters of appeal were sent to members of the hospital voluntary service, St John Ambulance Brigade and Red Cross Society.

The group consisted of 16 women and four men, aged 38-69 years (mean 49 years) with body mass or Quetelet index 18-33.6 (mean 24.7), who admitted to three bowel actions per week or less, or who often strained to pass scybalous faeces and whose whole gut transit time was 70 hours or longer. Volunteers admitting to alternating constipation and diarrhoea were excluded. Those who were already taking laxatives, bran or bran containing cereals were instructed to stop them for at least four weeks before entering the study. Ten subjects were taking other drugs (four diuretics, two antihypertensives, two antidepressants, one each temazepam, ibuprofen, non-cyclical progesterone and non-cyclical combined oestrogen and progesterone preparation) but the dosages remained unaltered during the study. Baseline measurements of transit time, bile composition and deoxycholic acid pool size and kinetics were carried out. Dietary intake was assessed by an experienced dietitian using a questionnaire and a 48 hour weighed record. The data obtained were analysed using a computer program compiled from standard food tables. ${ }^{10}$ Subjects were then prescribed a concentrated wheat-fibre preparation, Testa Triticum Tricum (Trifyba-Labaz), containing $80 \%$ dietary fibre by weight, which is manufactured by treating wheat bran enzymatically to remove starch, protein, and phytic acid. Subjects were instructed to take one or more sachets, each containing $3.5 \mathrm{~g}$ of Testa Triticum Tricum, with meals, in a dose sufficient to relieve their constipation (10-32 g daily) for a minimum of six weeks. Adequate response to treatment was monitored by one of us (SNM) by regular telephone calls. At the end of this period the transit time, biliary studies and dietary assessment were repeated.

In six of the volunteers, baseline measurements while they were constipated were obtained several weeks before starting Testa Triticum Tricum. In the meantime they had been treated with sennoside B (15-45 mg daily) for at least six weeks and had been restudied. They were included because it was known or expected that their baseline bile was supersaturated with cholesterol, which had not been the case with most of the subjects up till that time. It was considered important to have an adequate group of subjects whose bile was usually supersaturated. Unfortunately, all but one of these subjects refused to undergo a 'wash-out' period without taking any form of laxative because they were unhappy about becoming constipated again. In order to ensure that, in these five subjects, the effects of senna laxative on the bile had worn off and that any changes in bile composition could be credited to Testa Triticum Tricum, the latter was prescribed for a minimum of 12 weeks before bile was collected for repeat analysis.

Subjects had blood taken for liver function tests and these were normal. Fasting lipids were also measured and these were normal or only slightly raised. Ultrasound scan of the gall bladder showed the absence of gall stones in all. Four subjects were excluded from the study, one because of gall stones, one because of non-compliance and two because of failed intubation. The protocol of the study was reviewed and accepted by the District Ethical Committee of the Bristol and Weston Health Authority.

\section{WHOLE GUT TRANSIT-TIME}

Transit time was measured by the single stool method $^{11}$ with two modifications. While constipated, subjects ingested a gelatine capsule containing 20 radio-opaque Portex markers at breakfast time on alternate days for one week (rather than on three consecutive days) and then collected their next two stools. Each day the markers were of a different shape and were taken in a predetermined order. Stools were excreted directly into gussetted polyethylene bags which were sealed and stored at $-20^{\circ} \mathrm{C}$ until radiographed. Whole gut transit time was calculated from each stool by counting the two most abundant markers and applying the formula:

Whole gut transit time $(h)=\frac{t 1 s 1+t 2 s 2}{s 1+s 2}$

where $\mathrm{t} 1$ and $\mathrm{t} 2=$ time in hours from the ingestion of the two markers and $s 1$ and $s 2=$ the number of each 
marker present. The mean value from the two stools was then taken.

BILE COMPOSITION AND THE POOL SIZE AND

KINETICS OF DEOXYCHOLIC ACID

Three hours after the last meal of the day $0.37 \mathrm{MBq}$ $(10 \mu \mathrm{C}) 24^{14} \mathrm{C}$ deoxycholic acid, with a specific activity of $5.33 \mathrm{MBq} / \mathrm{mg}$ and radiochemical purity on thin layer chromatography of $96 \%$ (Radiochemical Centre, Amersham), was injected intravenously and, after an overnight fast, bile rich duodenal fluid was collected by means of duodenal intubation and cholecystokinin injection. The period of fasting was standardised for each volunteer. ${ }^{12}{ }^{13}$ In 11 volunteers $5 \mathrm{ml}$ aliquots of duodenal bile were collected on four consecutive mornings to enable determination of deoxycholic acid pool size, input and fractional turnover. ${ }^{14}$ In the remaining nine subjects who were unwilling to have repeated intubations, deoxycholic acid pool was determined by a slightly modified version of the 'one shot' technique. ${ }^{15}$

Total bile salt, phospholipid and cholesterol concentrations were measured ${ }^{16}$ and the cholesterol saturation index of bile was determined by the method of Thomas and Hofmann ${ }^{17}$ according to the criteria of Hegardt and Dam. ${ }^{18}$ In the small number of samples in which the total lipid concentration was $<20 \mathrm{mmol} / \mathrm{l}$ phospholipid concentration was measured using an enzymatic method. ${ }^{19}$

After enzymatic deconjugation and thin layer chromatographic separation of the dihydroxy bile acids $^{20}$ deoxycholic acid mass was determined by subtracting the $7 \alpha$ - from the $3 \alpha$-hydroxysteroid dehydrogenase results (Sigma Chemical Co.). ${ }^{6}$ The mass of the separated cholic acid was determined using $3 \alpha$-hydroxysteroid dehydrogenase. Radioactivity was measured by liquid scintillation counting. The counts were corrected for any effects due to quenching using quench curves calculated from external standards of ${ }^{14} \mathrm{C}$.

Table 1 Dietary intake of 20 constipated subjects before and during supplementation of their diet with Testa Triticum Tricum (Mean over $24 h \pm S D$ )

\begin{tabular}{lccl}
\hline & Before & During & $p$ value \\
\hline Energy (kcal) & $1734 \pm 542$ & $1745 \pm 562$ & NS \\
Total sugar $(\mathrm{g})$ & $76 \pm 36$ & $79 \pm 48$ & NS \\
Added sugar $(\mathrm{g})$ & $45 \pm 25$ & $48 \pm 35$ & NS \\
Total fibre $(\mathrm{g})$ & $22 \pm 7$ & $20 \pm 7^{*}$ & NS \\
Cereal fibre $(\mathrm{g})$ & $10 \pm 5$ & $9 \pm 5^{*}$ & NS \\
Protein (g) & $65 \pm 20$ & $67 \pm 22$ & NS \\
Fat (g) & $69 \pm 25$ & $73 \pm 26$ & NS \\
Carbohydrate (g) & $216 \pm 93$ & $207 \pm 82$ & NS \\
\hline
\end{tabular}

${ }^{*}$ Excludes the contribution due to Testa Triticum Tricum

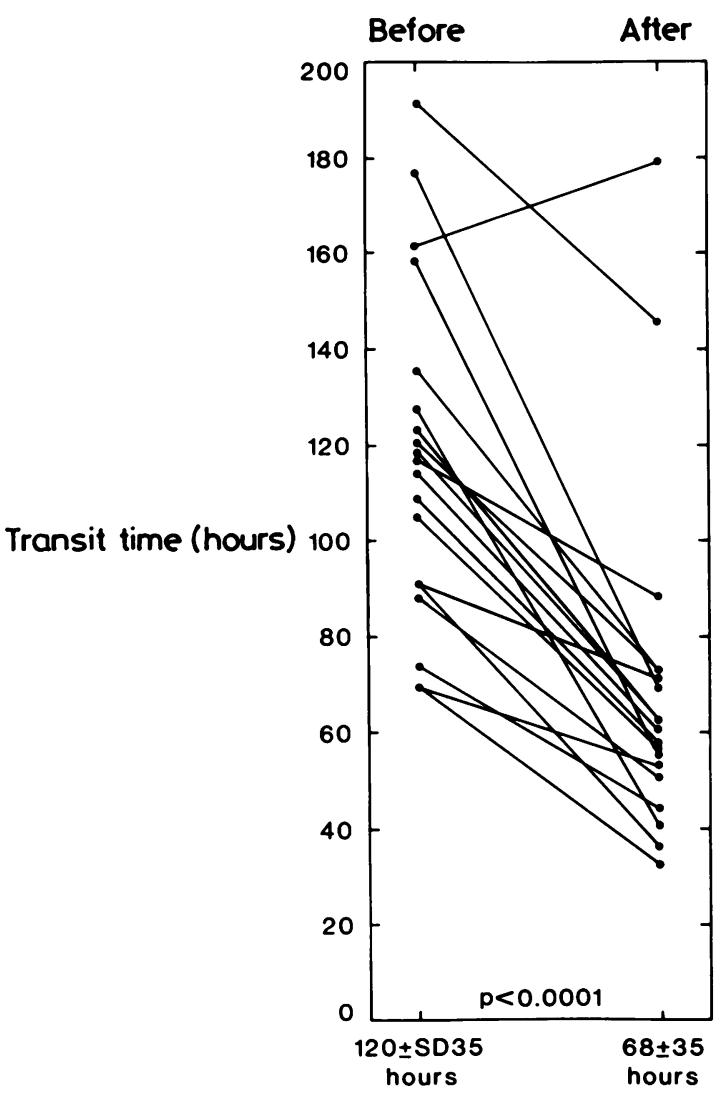

Fig. 1 Whole gut transit-time in 20 constipated subjects before and after adding Testa Triticum Tricum to their diet for at least six weeks.

From the data, the pool size, half life and input of deoxycholic acid were determined as well as the relative proportions of the three major bile acids. By combining these data the size of the total bile acid pool was estimated, accepting that a slight systematic underestimate of cholic acid is likely using this method.

\section{STATISTICAL ANALYSIS}

Student's paired $t$ test was used for determining the significances of differences. A $p$ value of $<0.05$ was taken as significant. Results are expressed as mean $\pm \mathrm{SD}$.

\section{Results}

\section{DIETARY INTAKE AND BODY MASS (QUETELET)} IN DEX

Dietary intake (Table 1) and body mass index $(24 \cdot 6 \pm 3 \cdot 1$ before and $24 \cdot 7 \pm 3 \cdot 1$ after) remained unaltered throughout the study. 
WHOLE GUT TRANSIT-TIME (Fig. 1).

With Testa Triticum Tricum transit time fell in all but one subject, the mean decreasing from $120 \pm 35 \mathrm{~h}$ to $68 \pm 35 \mathrm{~h}(\mathrm{p}<0 \cdot 001)$.

\section{RELATIVE PROPORTIONS OF BILE ACIDS IN BILE}

(Fig. 2)

The proportion of deoxycholic acid fell from $26 \cdot 6 \pm 12 \cdot 0 \%$ to $23 \cdot 8 \pm 11 \cdot 8 \%(p=0 \cdot 002)$. Conversely the proportion of cholic acid rose from $37 \cdot 6 \pm 6 \cdot 2 \%$ to $40.9 \pm 8.0 \%(p=0.008)$. The proportion of chenodeoxycholic acid did not alter significantly with treatment $(35.9 \pm 9.4 \%$ before and $36 \cdot 2 \pm 10.7 \%$ after).

DEOXYCHOLIC ACID POOL (Fig. 3)

With treatment the deoxycholic acid pool did not alter significantly $(0.64 \pm 0.38 \mathrm{~g}$ before and $0 \cdot 66 \pm 0.43 \mathrm{~g}$ after).
TOTAL BILE ACID POOL (Fig. 4)

Testa Triticum Tricum increased the total bile acid pool by $16 \%$ from $2 \cdot 36 \pm 0.88$ to $2 \cdot 75 \pm 0.99 \mathrm{~g}$ $(\mathrm{p}=0 \cdot 008)$.

CHOLESTEROL SATURATION INDEX (Fig. 5)

In 12 subjects whose initial cholesterol saturation index was $>1 \cdot 0$, Testa Triticum Tricum lowered the index in nine, the group mean decreasing from $1.33 \pm 0.25$ to $1 \cdot 22 \pm 0.21 \quad(p=0.008)$. Eight of the same 12 subjects had an initial cholesterol saturation index $>1 \cdot 2$, which on treatment fell in all eight from a mean of $1.46 \pm 0.79$ to $1.28 \pm 0.13(p<0.0001)$. Taking the whole group of 20 , the cholesterol saturation index fell from $1 \cdot 13 \pm 0.32$ to $1 \cdot 07 \pm 0.29$ $(p=0 \cdot 04)$.

DEOXYCHOLIC ACID KINETIC STUDIES

In the 11 subjects in whom it was measured, there
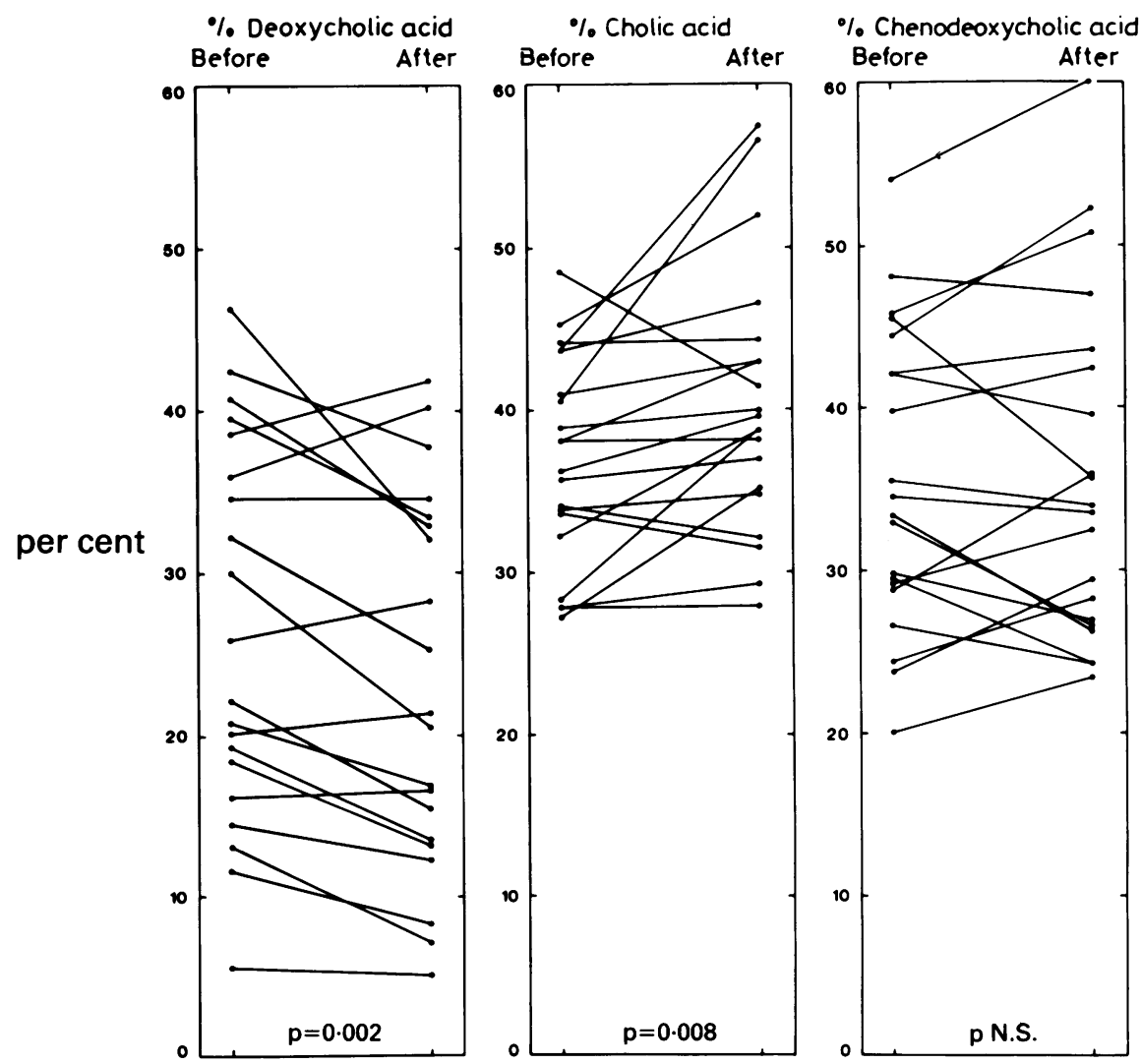

Fig. 2 Relative proportions of bile acids in bile acid pool in 20 constipated subjects before and after adding Testa Triticum Tricum to their diet for at least six weeks. 


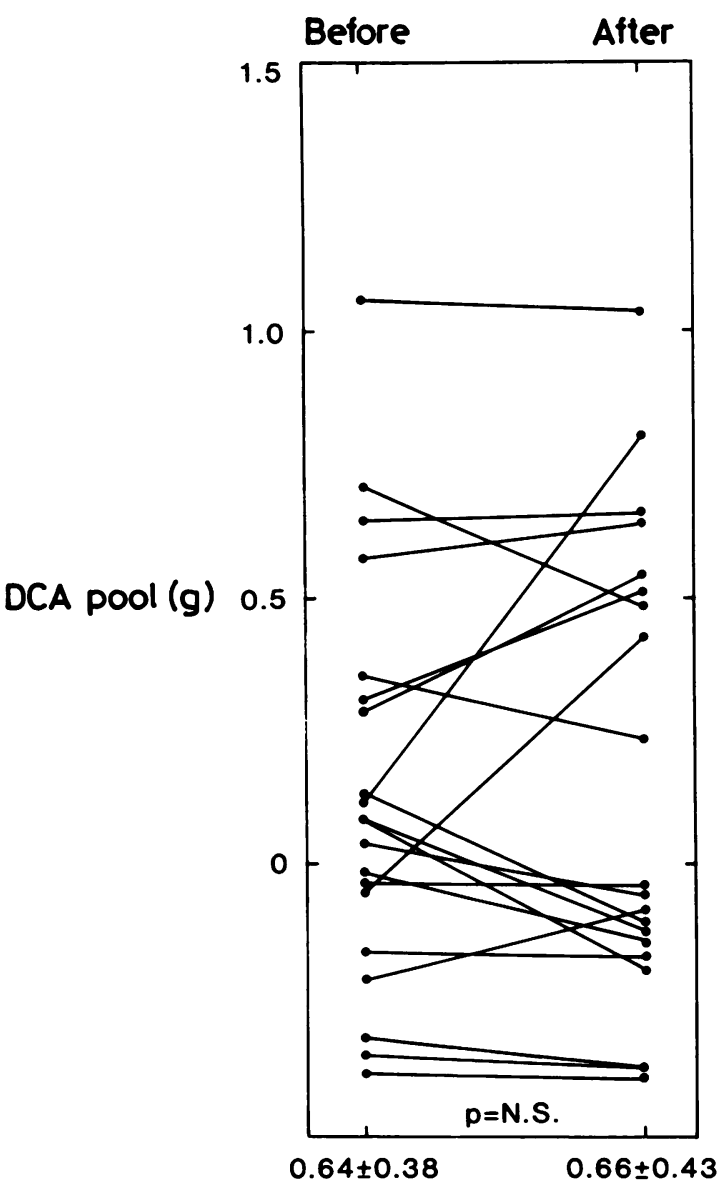

Fig. 3 Deoxycholic acid (DCA) pool in 20 constipated subjects before and after adding Testa Triticum Tricum to their diet for at least six weeks.

was no overall change in deoxycholic acid half-life $(4 \cdot 3 \pm 2 \cdot 2$ to $3 \cdot 5 \pm 1 \cdot 4$ days; NS).

Deoxycholic acid input increased slightly from $0 \cdot 14 \pm 0 \cdot 09$ to $0 \cdot 15 \pm 0.08 \mathrm{~g}$ daily $(\mathrm{p}=0 \cdot 014)$. Such a small increase is unlikely to have been of biological significance.

CORRELATIONS (Table 2)

Correlations between changes in transit and changes in bile composition before and after Testa Triticum Tricum were determined. There were no significant correlations between change in cholesterol saturation index and change in deoxycholic acid \% or deoxycholic acid pool, nor between change in transit-time and change in deoxycholic acid \% or deoxycholic acid pool, nor between change in transit time and change in cholesterol saturation index.
There was a significant inverse correlation between change in deoxycholic acid pool and change in chenodeoxycholic acid \% and between change in deoxycholic acid \% and change in cholic acid \%.

\section{Discussion}

As expected, Testa Triticum Tricum reduced the cholesterol saturation of bile when this was initially

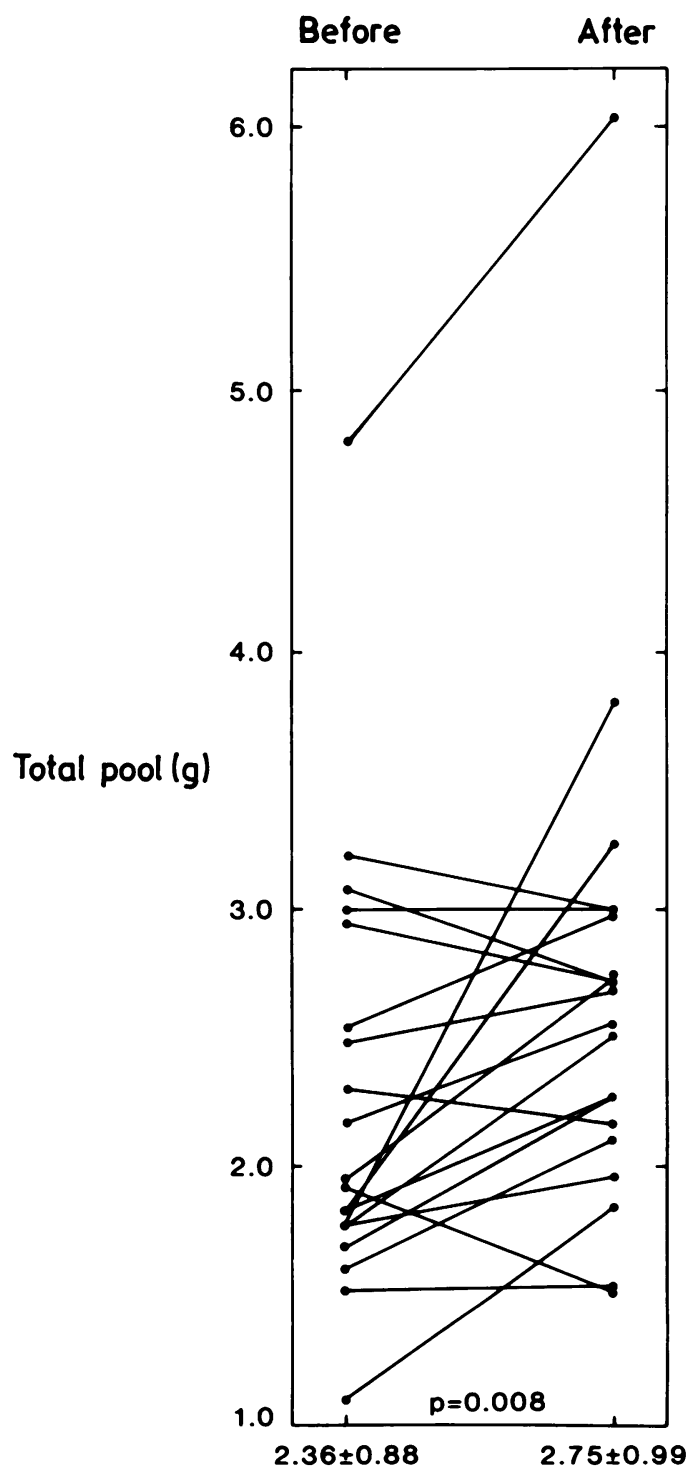

Fig. 4 Total bile acid pool in 20 constipated subjects before and after adding Testa Triticum Tricum to their diet for at least six weeks. 


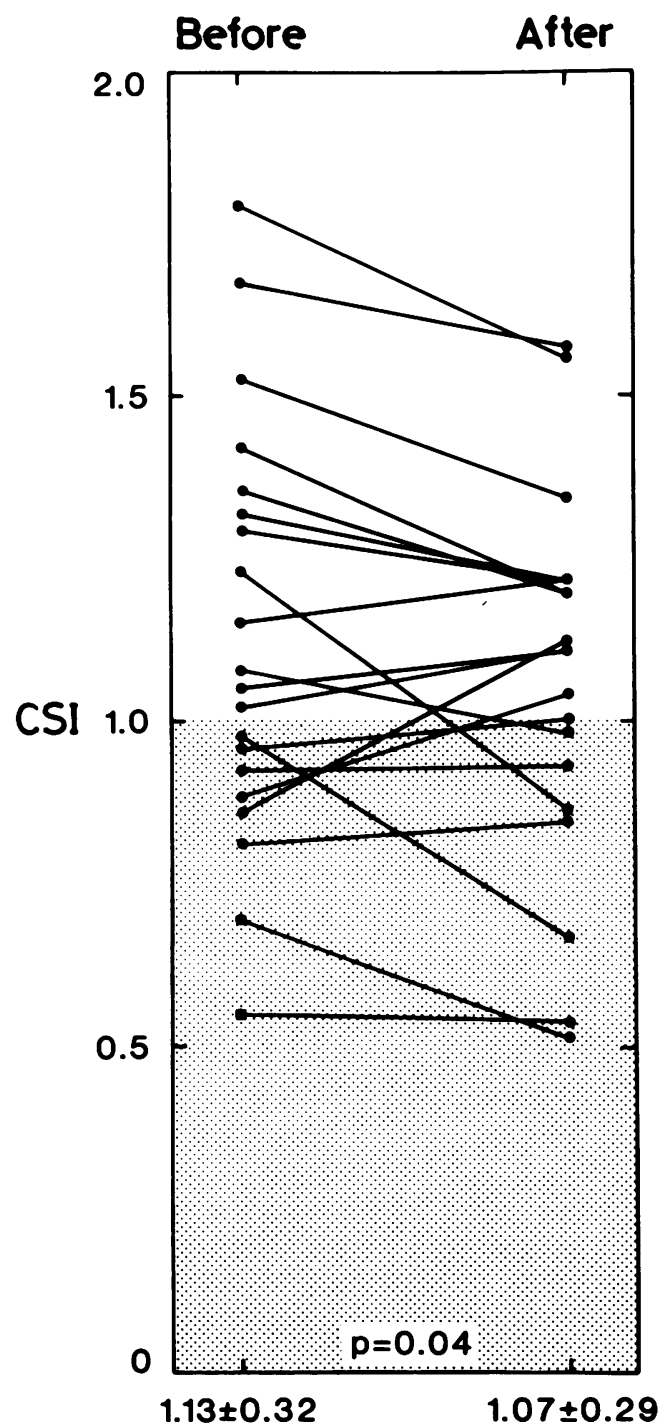

Fig. 5 Cholesterol saturation index (CSI) of bile-rich duodenal fluid in 20 constipated subjects before and after adding Testa Triticum Tricum to their diet for at least six weeks.

raised, though to a modest degree. It is difficult to compare its efficacy with that of ordinary bran because, in the published studies, there have been variations in the subjects studied, in the type and amount of bran and in the duration of its administration. Quite impressive reductions in cholesterol saturation index have been reported in some bran studies, however-for example, from 1.43 to $0.76^{3}$ and from $1 \cdot 01$ to $0 \cdot 67 .^{4}$ The relatively low efficacy of
Testa Triticum Tricum cannot be blamed on a poor effect on colonic transit, because subjects have responded very well in this respect in both the present study and in a previous study in constipated subjects. $^{21}$

Our other studies have suggested that there are correlations between changes in whole gut transit time, biliary deoxycholic acid and the cholesterol saturation of bile. ${ }^{8}$ Such correlations were not evident in the present study. Perhaps, these variables are dissociated in the presence of wheat fibre products. In the present study, one subject's transit time remained long yet her biliary deoxycholic acid fell (from 19.4 to $13.5 \%$ ), while Pomare and Heaton $^{5}$ reported three subjects whose transit times actually increased on bran yet their biliary deoxycholic acid levels fell.

Testa Triticum Tricum was less effective than expected from published bran studies in reducing deoxycholic acid levels in bile. Indeed there was no reduction at all in the size of the deoxycholic acid pool while deoxycholic acid input actually rose slightly. As the product is an effective laxative, this relative inefficacy could be taken as evidence that bran lowers biliary deoxycholic acid by some means other than by speeding up colonic transit. It has been proposed that, like lactulose, bran may act by acidifying the right colon, as short chain fatty acids are released when it is fermented by bacteria; the lowered $\mathrm{pH}$ could inhibit $7 \alpha$-dehydroxylase, the enzyme which aids the formation of deoxycholic acid from cholic acid. ${ }^{9}$ If this is the mode of action of bran, it raises the question why Testa Triticum Tricum should be less active than bran itself in being fermented into short chain fatty acids. Testa Triticum Tricum is quite powdery and small particles should be more readily attacked by bacterial enzymes. It differs from bran in containing no starch whereas bran is about $23 \%$ starch. ${ }^{10}$ This could be important if it is the undigested starch rather than the fibre in bran which is responsible for its effects on bile acid metabolism. Certainly, starch would be expected to be readily fermented by bacteria.

Reduction of biliary deoxycholic acid is the most plausible explanation for the beneficial action of bran on the cholesterol saturation of bile. ${ }^{122}$ In the case of Testa Triticum Tricum the mode of action is less clear because, although there was a fall in \% deoxycholic acid, there was no significant correlation between the change in \% deoxycholic acid (or the size of the deoxycholic acid pool) and change in cholesterol saturation index. Other mechanisms should also be considered. One possibility is expansion of the chenodeoxycholic acid pool. We did not measure this directly but presumably it increased as its contribution to the bile acid pool stayed the same 
Table 2 Correlation coefficients for changes in bile composition, bile acid pool sizes and whole gut transit time in 20 constipated subjects given Testa Triticum Tricum

\begin{tabular}{|c|c|c|c|c|c|c|c|}
\hline & $\triangle C A \%$ & $\triangle C D C A \%$ & $\triangle D C A \%$ & $\begin{array}{l}\triangle D C A \\
\text { pool }\end{array}$ & $\begin{array}{l}\Delta \text { Total bile } \\
\text { acid pool }\end{array}$ & $\Delta C S I$ & $\Delta$ Transit time \\
\hline $\begin{array}{l}\Delta \text { CA } \% \\
\Delta \text { CDCA } \% \\
\Delta \text { DCA } \% \\
\Delta \text { DCA pool } \\
\Delta \text { Total bile acid pool } \\
\Delta \text { CSI }\end{array}$ & & $-0.614 \dagger$ & $\begin{array}{l}-0.529^{*} \\
-0.345\end{array}$ & $\begin{array}{r}-0.028 \\
-0.480^{*} \\
0.542^{*}\end{array}$ & $\begin{array}{c}0.213 \\
-0.350 \\
0.115 \\
0.836 \ddagger\end{array}$ & $\begin{array}{r}-0 \cdot 341 \\
0 \cdot 231 \\
0 \cdot 159 \\
-0 \cdot 192 \\
-0 \cdot 309\end{array}$ & $\begin{array}{r}-0 \cdot 127 \\
0 \cdot 166 \\
-0 \cdot 036 \\
0 \cdot 255 \\
0 \cdot 205 \\
0 \cdot 068\end{array}$ \\
\hline
\end{tabular}

${ }^{*} \mathrm{p}<0.05+\mathrm{p}<0.01 \neq \mathrm{p}<0.001$

CA\% percent of cholic acid in bile acid pool; CDCA\% percent of chenodeoxycholic acid; DCA\% percent of deoxycholic acid; CSI cholesterol saturation index of bile-rich duodenal fluid.

while the bile acid pool expanded by about $16 \%$. The beneficial effect of expanding the chenodeoxycholic acid pool by administering the bile acid orally is of course well documented but it has not been shown that cholesterol saturation falls with such a minor expansion of the pool. Moreover, fall in cholesterol saturation is normally associated with a rise in \% chenodeoxycholic acid, not found by us. The cholic acid pool probably expanded as well because the proportion of cholic acid in the bile acid pool rose and so did the total bile acid pool. Expansion of the cholic acid pool, however, has not been shown to result in a fall in the cholesterol saturation of bile.

Previously, it has been suggested that a change in the proportion of deoxycholic acid in the bile acid pool results in a reciprocal change in the percentage of chenodeoxycholic acid, because of selective inhibition by deoxycholic acid of chenodeoxycholic acid synthesis. ${ }^{23}$ The validity of this relationship is, however, controversial. ${ }^{24-27}$ The present data are equivocal in that, while there was no significant correlation between changes in the percentages of these two bile acids, there was a weak but significant inverse correlation $(\mathrm{r}=-0.48)$ between change in the deoxycholic acid pool and change in \% chenodeoxycholic acid.

The questions raised by the present findings can only be answered when more is known of the interrelationships between colonic function and microbial metabolism of bile acids on the one hand and the effects of wheat fibre and starch on the other.

This work was made possible by generous support from Tricum AB, Höganas, Sweden and from Sanofi-Labaz, UK Ltd., Manchester. We are indebted to Tina Felton, and Ros Pratt, for their technical help and to Pauline Emmett, for her dietetic expertise. We are grateful to Dr Heather
Andrews, for scanning the gall bladders of our subjects.

\section{References}

1 Pomare EW, Heaton KW, Low-Beer TS, Espiner HJ. The effect of wheat bran upon bile salt metabolism and upon the lipid composition of bile in gallstone patients. Am J Dig Dis 1976; 21: 521-6.

2 Watts J McK, Jablonski P, Toouli J. The effect of added bran to the diet on the saturation of bile in people without gallstones. Am J Surg 1978; 135: 321-4.

3 McDougall RM, Yakymyshyn L, Walker K, Thurston OG. The effect of wheat bran on serum lipoproteins and biliary lipids. Can J Surg 1978; 21: 433-5.

4 Wechsler JG, Swobodnik W, Wenzel H, Heuchemer W, Nebelung W, Hutt V, Ditschuneit H. Ballaststoffe vom Typ Weizenkleie senken Lithogenität der Galle. Dtsche Med Wochenschr 1984; 109: 1284-8.

5 Pomare EW, Heaton $\mathrm{KW}$. Bile salt metabolism in patients with gallstones in functioning gall bladders. Gut 1973; 14: 885-90.

6 Wicks ACB, Yeates J, Heaton KW. Bran and bile: time-course of changes in normal young men given a standard dose. Scand J Gastroenterol 1978; 13: 289-92.

7 Huijbregts AWM, Van Berge-Henegouwen GP, Hectors MPC, Van Schaik A, Van der Werf SDJ. Effects of a standardised wheat bran preparation on biliary lipid composition and bile acid metabolism in young healthy males. Eur J Clin Invest 1980; 10: 451-8.

8 Marcus SN, Heaton KW. Intestinal transit rate, deoxycholic acid and the cholesterol saturation of bile - three inter-related factors Gut 1986; 27: 550-8.

9 Thornton JR, Heaton KW. Do colonic bacteria contribute to cholesterol gall-stone formation? Effects of lactulose on bile. $\mathrm{Br}$ Med $J$ 1981; 282: 1018-20.

10 Paul AA, Southgate DAT (eds.) McCance and Widdowson's the composition of foods. London: HMSO, 1978.

11 Cummings JH, Wiggins HS. Transit through the gut measured by analysis of a single stool. Gut 1976; 17: 219-23. 
12 Williams CN, Morse JWI, MacDonald IA, Kotoor R, Riding MD. Increased lithogenicity of bile on fasting in normal subjects. Am J Dig Dis 1977; 22: 189-94.

13 Bloch HM, Thornton JR, Heaton KW. Effects of fasting on the composition of gallbladder bile. Gut $1980 ; 21$ : $1087-9$.

14 Lindstedt S. The turnover of cholic acid in man. Acta Physiol Scand 1957; 40: 1-9.

15 Duane WC, Adler RD, Bennion LJ, Ginsberg RL. Determination of bile acid pool size in man: a simplified method with advantages of increased precision, shortened analysis time and decreased isotope exposure. J Lipid Res 1975; 16: 155-8.

16 Bolton CH, Low-Beer TS, Pomare EW, Wicks ACB, Yeates J, Heaton KW. A simplified procedure for the analysis of cholesterol, phospholipids and bile salts in human bile. Clin Chim Acta 1978; 83: 177-81.

17 Thomas PJ, Hofmann AF. A simple calculation of the lithogenic index of bile: expressing biliary lipid composition on rectangular co-ordinates. Gastroenterology 1973; 65: 698-700.

18 Hegardt FG, Dam H. The solubility of cholesterol in aqueous solutions of bile salts and lecithin. Z Ernährungsw 1971; 10: 223-33.

19 Werner D, Emmett PM, Heaton KW. Effects of dietary sucrose on factors influencing cholesterol gallstone formation. Gut 1984; 25: 269-74.
20 Thornton JR, Emmett PM, Heaton KW. Diet and gallstones: effects of refined and unrefined carbohydrate diets on bile cholesterol saturation and bile acid metabolism. Gut 1983; 24: 2-6.

21 Salvioli G, Di Simone A, Corazziari R, Riegler G. A safe and effective approach to chronic constipation with a new product made from wheat husks: Fibraform (Testa Triticum Tricum). Curr Ther Res 1984; 36: 24-8.

22 Heaton KW. The role of diet in the aetiology of cholelithiasis. Rev Clin Nutr 1984; 54: 549-60.

23 Pomare EW, Low-Beer TS. The selective inhibition of chenodeoxycholate synthesis by cholate metabolites in man. Clin Sci Mol Med 1975; 48: 315-21.

24 Ahlberg J, Angelin B, Einarsson K, Hellström K, Leijd B. Influence of deoxycholic acid on biliary lipids in man. Clin Sci Mol Med 1977; 53: 249-56.

25 Hofmann AF, Grundy SM, Lachin JM, et al. Pretreatment biliary lipid composition in white patients with radiolucent gallstones in the National Cooperative Gallstone Study. Gastroenterology 1982; 83: 738-52.

26 Van der Werf SDJ, Van Berge Henegouwen GP. Biliary bile acid composition and cholesterol saturation. Gastroenterology 1983; 84: 1074-7.

27 Hofmann AF, Lachin JM. Biliary bile acid composition and cholesterol saturation. Gastroenterology 1983; 84: 1075-7. 